\title{
Optic neuropathy in methylmalonic acidemia and propionic acidemia
}

\author{
Lidia Martinez Alvarez, ${ }^{1}$ Elisabeth Jameson, ${ }^{3}$ Neil R A Parry, ${ }^{1,2}$ Chris Lloyd, ${ }^{1,2}$ \\ Jane L Ashworth ${ }^{1,2}$
}

${ }^{1}$ Manchester Royal Eye Hospital, Central Manchester University Hospitals NHS Foundation Trust, Manchester Academic Health Sciences Centre, Manchester, UK ${ }^{2}$ Faculty of Medical and Human Sciences, Centre for Ophthalmology and Vision Sciences, Institute of Human Development, University of Manchester, Manchester, UK ${ }^{3}$ Willink Biochemical Genetics Unit, Manchester Centre for Genomic Medicine,

Manchester, UK

\section{Correspondence to} Jane Ashworth, Manchester Royal Eye Hospital, Oxford Road, Manchester M13 9WL, UK Jane.Ashworth@cmft.nhs.uk

Received 19 February 2015 Revised 16 June 2015 Accepted 29 June 2015 Published Online First 24 July 2015

\section{CrossMark}

To cite: Martinez Alvarez $\mathrm{L}$, Jameson E, Parry NRA, et al. $\mathrm{Br} J$ Ophthalmol

2016:100:98-104

\section{ABSTRACT}

Background Methylmalonic acidemia (MMA) and propionic acidemia (PA) are rare hereditary disorders of protein metabolism, manifesting early in life with ketoacidosis and encephalopathy and often resulting in chronic complications. Optic neuropathy (ON) has been increasingly recognised in both conditions, mostly through isolated case reports or small cases series. We here report the clinical features and visual outcomes of a case series of paediatric patients with a diagnosis of MMA or PA.

Methods Retrospective observational case series. A database of patients attending the Willink Biochemical Genetics unit in Manchester was interrogated. Fifty-three patients had a diagnosis of either isolated MMA or PA, of which 12 had been referred for ophthalmic review.

Results Seven patients had clinical findings compatible with ON. Visual outcomes in these patients were poor, with slow clinical progression or stability over time in five cases with follow-up. Presentation was acute in a context of metabolic crisis in two of the cases. Four patients with $\mathrm{ON}$ had electrodiagnostics showing absent pattern evoked potentials, with one showing a preserved flash response. All four showed marked attenuation of the dark-adapted electroretinogram with better preservation of the light-adapted response. Conclusions Our study suggests that $\mathrm{ON}$ is underreported in patients with MMA and PA. Clinical presentation can be acute or insidious, and episodes of acute metabolic decompensation appear to trigger visual loss. Photoreceptor involvement may coexist. Active clinical surveillance of affected patients is important as comorbidities and cognitive impairment may delay diagnosis.

\section{INTRODUCTION}

Methylmalonic acidemia (MMA) and propionic acidemia (PA) are two of the most common organic acidemias (OA). They are inherited defects of the catabolism of propionate, a common intermediate product of the catabolism of branched-chain amino acids and odd chain fatty acids, caused by variable deficient activity of two mitochondria-located enzymes: methylmalonyl-CoA mutase in MMA and propionyl-CoA carboxylase in PA. These two enzymes consecutively intervene in the conversion of propionate into succinate, which is then fed into the Krebs cycle to produce energy for the mitochondrial respiratory chain. Deficiencies of these enzymes result in the accumulation of intermediate upstream products: methylmalonate and propionate, respectively, alongside other toxic derivatives.

Patients with MMA and PA usually present in the neonatal period with acute metabolic distress
(AMD) and encephalopathy, but may present later in infancy in less severe deficiencies with recurrent ketoacidosis, psychomotor retardation and chronic vomiting. Treatment is based on a strict low-protein diet to limit enzymatic substrate, sufficient caloric intake, L-carnitine and antibiotics to reduce intestinal odd-chain, fatty acid-producing bacteria. Stress, infections and inadequate diet can trigger AMD. Despite significant therapeutic improvements over the last two decades, global outcome of patients with OA remains poor, with chronic complications remaining common and progressive. ${ }^{1-3}$

Although these enzymes are expressed ubiquitously, the clinical features observed indicate a tissue-specific vulnerability (brain, muscle, pancreas, kidney). Both conditions, but especially PA, ${ }^{1}$ often manifest with encephalopathy, causing permanent damage in the form of variable developmental delay and movement disorders, with frequent basal ganglia lesions on MRI and acute 'stroke-like' deficits. MMA also results in renal impairment in the first or second decade of life, whereas cardiac anomalies are common in PA.

Optic neuropathy $(\mathrm{ON})$ is an increasingly recognised complication in the course of both acidemias, but few case reports or series of cases in the literature describe it. ${ }^{4-7}$ We aimed to define the clinical features and electrodiagnostic findings of paediatric patients with MMA or PA.

\section{MATERIALS AND METHODS}

This study comprises a retrospective observational case series and literature review. The database of patients followed in the Willink Biochemical Genetics Unit with a diagnosis of PA or MMA was interrogated, yielding a total of 53 patients $(35$ with MMA and 18 with PA). Patients who had undergone ophthalmic examination were included for analysis. A literature search (keywords: methylmalonic acidemia, propionic acidemia, organic acidemia, optic neuropathy, optic atrophy, eye) identified previously published reports and case series of PA or MMA with ON.

\section{RESULTS}

A total of 12 patients had available ophthalmic records. Of these, seven children had fundus changes (optic atrophy or pallor) and reduced visual acuities compatible with $\mathrm{ON}$, whereas the remaining five did not show evidence of $\mathrm{ON}$ (normal optic nerve appearance and/or normal visual acuity (VA)). Clinical observations are summarised in table 1 for patients without visible ON and in table 2 for patients with ON. 
Table 1 Clinical features of patients without signs of optic neuropathy

\begin{tabular}{|c|c|c|c|c|c|c|c|c|}
\hline $\begin{array}{l}\text { Case } \\
\text { no. }\end{array}$ & $O A$ & Gender & $\begin{array}{l}\text { Follow-up } \\
\text { time }\end{array}$ & Age & $\begin{array}{l}\text { VA } 1 \\
\text { RE/LE }\end{array}$ & $\begin{array}{l}\text { VA } 2 \\
\text { RE/LE }\end{array}$ & Ophthalmic findings & Systemic disease progression \\
\hline 1 & MMA & M & 7 months & 16 & $\begin{array}{l}6 / 7.5 \\
6 / 7.5\end{array}$ & $\begin{array}{l}6 / 7.5 \\
6 / 7.5\end{array}$ & $\begin{array}{l}\text { Normal colour vision and } \\
\text { fundoscopy } \\
\text { Delayed pVEP. ERG not tested }\end{array}$ & $\begin{array}{l}\text { Onset infancy ( } 6 \text { months) } \\
\text { Renal impairment } 1 \mathrm{st} \text { decade with renal transplant } \\
\text { Extra pyramidal choreo-athetoid movement disorder } \\
\text { secondary to basal ganglia metabolic stroke }\end{array}$ \\
\hline 2 & MMA & M & 36 months & 2 & $\begin{array}{l}6 / 9 \mathrm{CC} \\
\text { binocular }\end{array}$ & $\begin{array}{l}6 / 9 \mathrm{CC} \\
\text { binocular }\end{array}$ & $\begin{array}{l}\text { Small angle esotropia, ocular } \\
\text { apraxia, nystagmus } \\
\text { Normal fundoscopy. Absent } \\
\text { pVEP, normal fVEP, normal ERG }\end{array}$ & $\begin{array}{l}\text { Global neurodevelopmental delay } \\
\text { Renal failure on peritoneal dialysis since aged } 3\end{array}$ \\
\hline 3 & MMA & M & 15 months & 2 & $\begin{array}{l}6 / 12 \mathrm{CC} \\
\text { binocular }\end{array}$ & $\begin{array}{l}6 / 12 \mathrm{CC} \\
\text { binocular }\end{array}$ & Normal fundoscopy & $\begin{array}{l}\text { Neonatal onset } \\
\text { Colitis and dermatitis }\end{array}$ \\
\hline 4 & PA & M & 22 months & 8 & $\begin{array}{l}6 / 6 \\
6 / 6\end{array}$ & $\begin{array}{l}6 / 6 \\
6 / 6\end{array}$ & Normal fundoscopy & $\begin{array}{l}\text { Neonatal onset } \\
\text { Autistic disorder }\end{array}$ \\
\hline 5 & PA & M & NA & 12 & NA & NA & $\begin{array}{l}\text { Alternating esotropia } \\
\text { Normal fundoscopy }\end{array}$ & $\begin{array}{l}\text { Onset in infancy } \\
\text { Developmental delay } \\
\text { Myopathy, prolonged Q-T }\end{array}$ \\
\hline
\end{tabular}

Age, recorded at first ophthalmic examination; CC, Cardiff Cards; ERG, electroretinogram; F, female; fVEP, flash visual evoked potential; LE, left eye; M, male; MMA, methylmalonic acidemia; NA, not available; $O A$, organic acidemias; PA, propionic acidemia; pVEP, pattern visual evoked potential; $R E$, right eye; VA 1, initial visual acuity; VA 2, final visual acuity.

In the group of patients without $\mathrm{ON}$ (table 1), one patient (patient 2) had esotropia, ocular apraxia and nystagmus but no fundal evidence of ON. Their pattern visual evoked potential (VEP) was extinguished, but the flash response was normal. Another patient (patient 1) showed delayed pattern VEP, but normal fundoscopy and visual function. In the remaining three, electrodiagnostics were not performed: of these, one child had esotropia but normal fundoscopy (patient 5) and two did not have abnormal ocular findings.

Ages in children with visible ON (table 2) ranged between 6 and 14 years, with a mean of 10 years. There was a male preponderance, with five males and two females; of three patients with PA, two were male and one female. Out of four patients with MMA, three were male and one female. All showed a degree of optic nerve pallor that was subtle in two cases (8 and 10) and severe in the remaining five, with unremarkable retinal examination.

Clinical presentation of $\mathrm{ON}$ was progressive, insidious or undetermined in five children, and acute or subacute in two. Three had strabismus on examination, and one reported temporary esotropia during previous illness. Of those who presented insidiously, $\mathrm{ON}$ was detected in routine eye referrals for esotropia in two. Two children were referred with a history of long-standing visual difficulties and in another child the onset of visual loss could not be determined (figure 1).

Two children (cases 8 and 12) presented acutely with complaints of visual loss during episodes of AMD that required long hospital admissions and intensive care with other concomitant complications such as pancreatitis (case 12), and worsening spasticity in case 8 , both requiring ventilation and tracheotomy (figure 2). Case 8 only had partial visual improvement following stabilisation. A third patient (case 6) had acute worsening of his VA during AMD secondary to an episode of posterior reversible encephalopathy in a context of renal failure and hypertension.

VA at presentation of ON was worse than 6/60 (Snellen) in five eyes, between $6 / 60$ and $6 / 30$ in seven eyes and only two eyes were better than $6 / 30$ (table 2). Follow-up after diagnosis was available in five children, ranging between 12 and 48 months, with a median of 20 months. All deteriorated or were stable over time, except case 8 , who experienced a partial improvement in VA. Final VA was worse than $6 / 60$ for four eyes, between $6 / 48$ and 6/30 in four eyes and better than 6/30 in two.
Four children had International Society for Clinical Electrophysiology of Vision standard electrodiagnostics (cases 6, 7, 10 and 12). Pattern VEPs were absent in all four, as were flash responses in three of them. All four showed marked electroretinogram (ERG) attenuation, particularly in the dark-adapted state (by about $80 \%$ ), but also to some extent (about 50\%) in the light-adapted state (figure 3).

Out of the four children with MMA and ON, all had some degree of renal failure and neurological involvement at diagnosis. Renal failure was severe in three, necessitating a renal transplant in two. Two had MRI evidence of damage to the basal ganglia and another had leg spasticity; one had behavioural problems and other, mild learning difficulties. In the three children with PA and ON, two had significantly prolonged Q-T intervals. Two had developmental delay, along with epilepsy in one case, and other showed MRI changes in the basal ganglia; the third child had generalised myopathy. B12 levels were measured in several occasions during follow-up under the metabolic unit, and these were within normal limits.

\section{DISCUSSION}

From our database of 53 patients with MMA and PA, 12 patients underwent ophthalmic review and 7 of these had clinical signs of $\mathrm{ON}$, suggesting an incidence of $\mathrm{ON}$ of at least $13 \%$ in these patients. Two of the five patients without clinical signs of $\mathrm{ON}$ also had subnormal VEPs indicating subclinical involvement.

Other authors have reported a visual impairment rate of $7 \%$ in OA, with no details provided regarding the aetiology of the visual loss. ${ }^{2}$ Our findings suggest that the incidence of visual impairment is likely to be higher. Whereas five patients with ON were referred with a complaint of visual difficulties or visual loss, two were found to have clinical $\mathrm{ON}$ and a further two subclinical ON during ophthalmic screening, and this seems to also have been the case in at least two other paediatric patients reported in the literature. ${ }^{4}$ The remaining 41 patients under metabolic follow-up that were not referred to our department for examination were not recognised as having visual impairment. However, the very common coexistence of developmental delay and other severe chronic, life-threatening complications would be potential factors contributing to under-diagnosis. 
Table 2 Clinical features of patients with signs of optic neuropathy

\begin{tabular}{|c|c|c|c|c|c|c|c|c|c|}
\hline $\begin{array}{l}\text { Case } \\
\text { no. }\end{array}$ & $\mathrm{OA}$ & Gender & $\begin{array}{l}\text { Follow- up } \\
\text { time }\end{array}$ & Age & $\begin{array}{l}\text { VA } 1 \\
\text { RE/LE }\end{array}$ & $\begin{array}{l}\text { VA } 2 \\
\text { RE/LE }\end{array}$ & Ophthalmic findings & $\begin{array}{l}\text { Clinical presentation } \\
\text { Acute/progressive }\end{array}$ & Systemic disease progression \\
\hline 6. & MMA & M & 20 months & 12 & $\begin{array}{l}6 / 38 \\
6 / 38\end{array}$ & LP $6 / 48$ & $\begin{array}{l}\text { Bilateral ONP } \\
\text { Absent pVEP and fVEP Attenuated ERG } \\
\text { (dark-adapted more so than light-adapted) } \\
\text { Exotropia }\end{array}$ & $\begin{array}{l}\text { Progressive loss of vision over } 2 \text { years. } \\
\text { Further drop in VA to LP and CF during } \\
\text { AMD and episode of PRES }\end{array}$ & $\begin{array}{l}\text { Neonatal onset } \\
\text { Poor weight gain } \\
\text { Renal failure in the 1st decade of life with renal } \\
\text { transplant } \\
\text { MRI changes basal ganglia } \\
\text { Behavioural problems } \\
\text { Deceased } 3 \text { years after ON diagnosis }\end{array}$ \\
\hline 7. & MMA & M & 48 months & 6 & $\begin{array}{l}6 / 48 \\
6 / 15\end{array}$ & $\begin{array}{l}6 / 48 \\
6 / 48\end{array}$ & $\begin{array}{l}\text { Bilateral temporal ONP } \\
\text { Absent pVEP and fVEP Attenuated ERG } \\
\text { (dark-adapted more so than light-adapted) } \\
\text { Esotropia }\end{array}$ & $\begin{array}{l}\text { Insidious ('struggle with eyes') with low } \\
\text { gradual decline in the left eye to match } \\
\text { VA in fellow eye }\end{array}$ & $\begin{array}{l}\text { Neonatal onset } \\
\text { Encephalopathy and severe acidosis as a new-born } \\
\text { Learning difficulties } \\
\text { Mild renal failure in the 1st decade of life }\end{array}$ \\
\hline 8. & MMA & $\mathrm{F}$ & 15 months & 12 & $\begin{array}{l}6 / 60 \\
6 / 60\end{array}$ & $\begin{array}{l}6 / 9.5 \\
6 / 30\end{array}$ & $\begin{array}{l}\text { Mild bilateral temporal ONP } \\
\text { OCT RNFL thinning } \\
\text { Dyschromatopsia }\end{array}$ & $\begin{array}{l}\text { Acute onset during AMD, decline over } \\
3 \text { months from initial VA record of } 6 / 7.5 \\
\text { and } 6 / 9 \text { with spontaneous partial } \\
\text { recovery } 4 \text { months later }\end{array}$ & $\begin{array}{l}\text { Neonatal onset } \\
\text { Basal ganglia infarct at age 3, movement disorders } \\
\text { Renal end-stage impairment during 1st decade. } \\
\text { Cardiac: long Q-T } \\
\text { Multiple periods of AMD }\end{array}$ \\
\hline 9. & MMA & M & NA & 10 & $\begin{array}{l}1 / 60 \\
1 / 60\end{array}$ & NA & Bilateral ONP & Undetermined & $\begin{array}{l}\text { Infancy onset (4 months) } \\
\text { Renal failure 1st decade of life with renal transplant } \\
\text { Inferior limb spasticity } \\
\text { Haemorrhagic pancreatitis } \\
\text { Deceased months after ONP diagnosis }\end{array}$ \\
\hline 10. & PA & M & 12 months & 14 & $\begin{array}{l}6 / 12 \\
6 / 36\end{array}$ & $\begin{array}{l}6 / 24 \\
1 / 60\end{array}$ & $\begin{array}{l}\text { Normal optic discs } \\
\text { Dyschromatopsia } \\
\text { Absent pVEP, reduced fVEP } \\
\text { Attenuated dark-adapted ERG } \\
\text { Esotropia }\end{array}$ & $\begin{array}{l}\text { Insidious } \\
\text { Detected on screening for esotropia/ } \\
\text { hypermetropia } \\
\text { Progressive decline of VA over } 12 \text { months }\end{array}$ & $\begin{array}{l}\text { Infancy onset ( } 45 \text { months) } \\
\text { Encephalopathy as an infant with seizures and resolved } \\
\text { dystonia } \\
\text { Basal ganglia changes MRI } \\
\text { Learning difficulties } \\
\text { Developmental delay+ } \\
\text { Prolonged QT } \\
\text { Congenital hypothyroidism }\end{array}$ \\
\hline 11. & PA & M & NA & 7 & $\begin{array}{l}\text { Fix and } \\
\text { follow toy BE }\end{array}$ & NA & Bilateral severe ONP & $\begin{array}{l}\text { Insidious } \\
\text { Detected on screening due to temporary } \\
\text { esotropia in episode of metabolic } \\
\text { decompensation }\end{array}$ & $\begin{array}{l}\text { Neonatal presentation } \\
\text { Developmental delay ++ } \\
\text { Seizures } \\
\text { Multiple admissions for decompensation } \\
\text { Borderline long Q-T }\end{array}$ \\
\hline 12. & PA & $\mathrm{F}$ & 34 months & 11 & $\begin{array}{l}\mathrm{HM} \\
6 / 60\end{array}$ & $\begin{array}{l}\mathrm{HM} \\
\mathrm{CF}\end{array}$ & $\begin{array}{l}\text { Bilateral temporal ONP } \\
\text { Dyschromatopsia } \\
\text { Absent pVEP and fVEP } \\
\text { Attenuated ERG (dark-adapted more so than } \\
\text { light-adapted) }\end{array}$ & $\begin{array}{l}\text { Acute onset/ worsening of previous } \\
\text { undetected ON during acute metabolic } \\
\text { decompensation and pancreatitis. No } \\
\text { response to CoQ10. Optic cupping } \\
\text { developed months later, with slow } \\
\text { deterioration over } 2 \text { years }\end{array}$ & $\begin{array}{l}\text { Neonatal presentation } \\
\text { Multiple admissions for AMD } \\
\text { Acute pancreatitis } \\
\text { Generalised myopathy with dyspnoea } \\
\text { Prolonged Q-T }\end{array}$ \\
\hline
\end{tabular}

Age, recorded at first ophthalmic examination; AMD, acute metabolic decompensation; CF, counting fingers; CoQ10 co-enzymeQ10; ERG, electroretinogram; F, female; fVEP, flash visual evoked potential; HM, hand movements; LE, left eye; LP, light perception; M, male; MMA, methylmalonic acidemia; NA, not available; OA, organic acidemias; OCT, optical coherence tomography; ON, optic neuropathy; ONP, optic nerve pallor; PA, propionic acidemia; PRES, posterior reversible encephalopathy syndrome; pVEP, pattern visual evoked potential; RE, right eye; RNFL, retinal nerve fibre layer; VA 1, initial visual acuity; VA 2, final visual acuity.

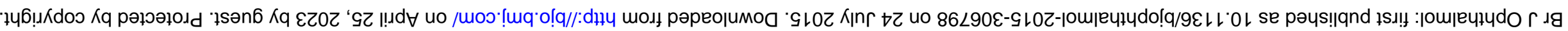


Figure 1 Top: Fundal pictures show diffuse optic nerve pallor in a 14-year-old male (case no. 6 in the table) with methylmalonic acidemia of neonatal onset, complicated with end-stage renal failure necessitating transplant. Final visual acuity was light perception in the right eye and 6/48 in the left. Bottom: Bilateral optic atrophy in an 11-year-old female (case no. 12 in the table) with propionic acidemia diagnosed days after birth. Marked optic cupping is observed, found to have developed 24 months after acute bilateral loss of vision during a metabolic crisis. Initial cup/disc ratio was 0.2 for either eye. Visual acuity was hand movements and $6 / 60$ for right and left eyes, respectively. Both cases had electrodiagnostics, showing absent evoked potentials and decreased dark-adapted responses on electroretinography. RNFL, retinal nerve fibre layer.

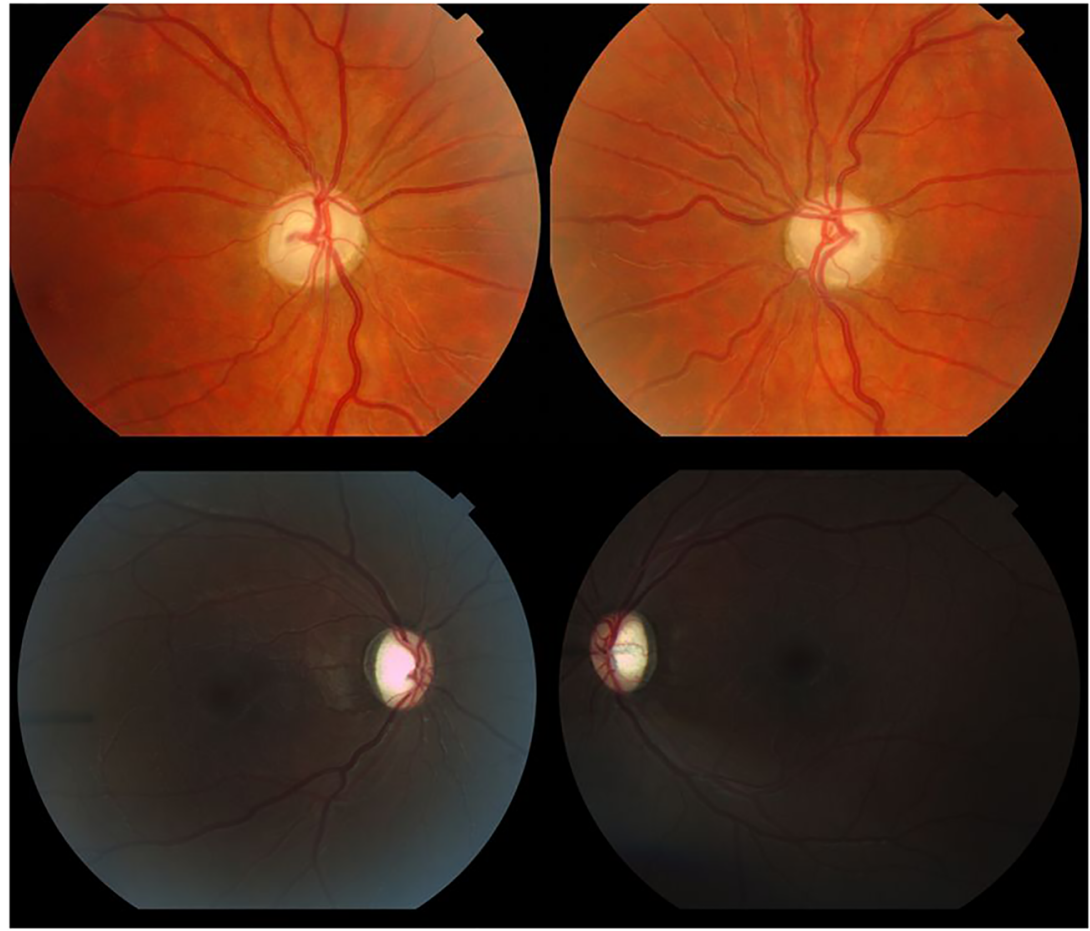

Previously reported ocular findings in PA and MMA have included $\mathrm{ON}$, cataracts and ocular apraxia. A literature search identified 11 patients with MMA or PA with a diagnosis of ON. $^{4-9}$ Details of these patients are summarised in table 2. A distinct subtype of MMA associated with a specific deficiency in the cobalamin metabolism (CblC subtype) is known to manifest with a prominent maculopathy and retinopathy, which has been well described in the literature. ${ }^{10}$ We have excluded these patients from our review and database search due to their different ocular and systemic phenotype.

The mean age of patients previously reported with MMA and PA and optic atrophy was higher than our series (15.5 years), with ranges between 2 and 24 years old. Those who were older at diagnosis were better characterised clinically, with acute bilateral loss of vision in six, and sequential visual loss in two. Perimetry showed centro-cecal scotomas in four reported cases and a concentric scotoma in one patient. Those who were younger (13 years old or less) were either detected in screening ${ }^{4}$ or presentation was undetermined. Visual outcome for 20 eyes was poor with a VA below 6/60; only one patient had a better outcome (patient 4 in table 3 ), who had fluctuating vision in the previous months and a partial recovery after starting antioxidant treatment. Two patients had VEP, and both showed delayed responses.

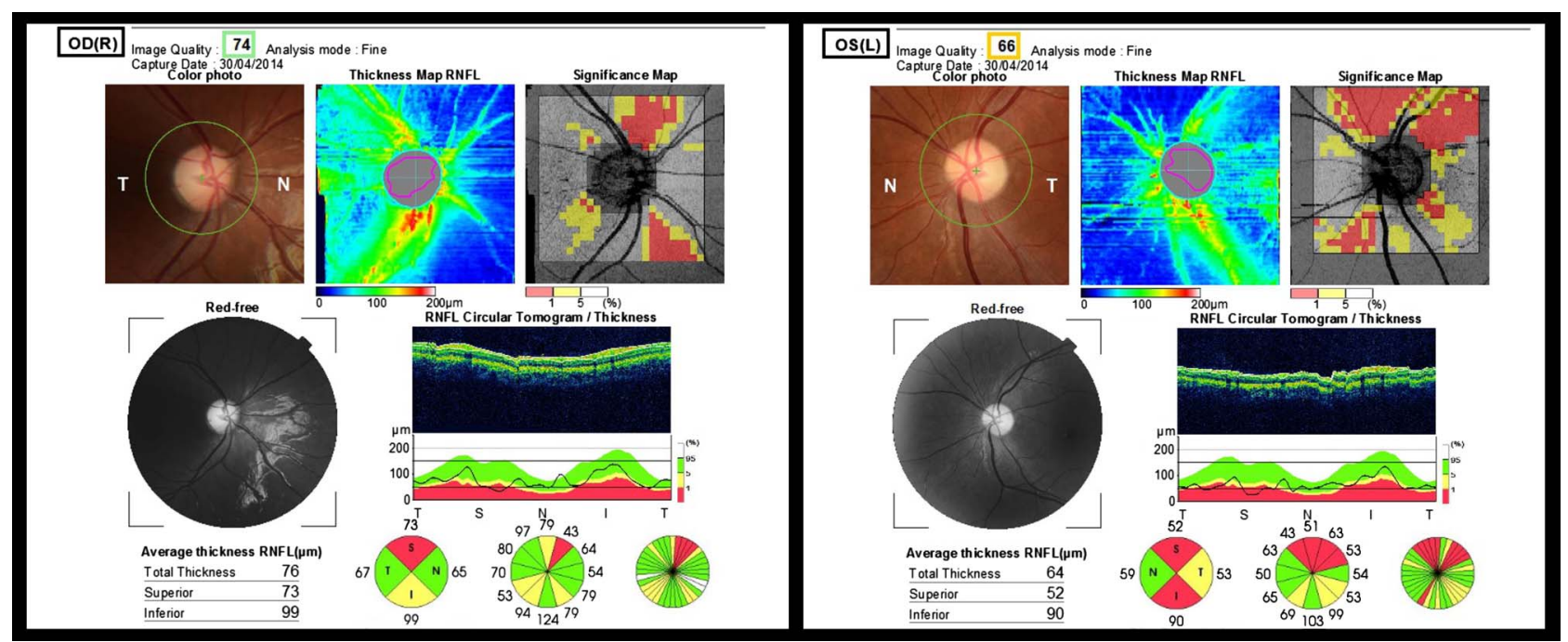

Figure 2 Topcon optical coherence tomography (OCT) of the retinal nerve fibre layer and fundal pictures of an 11-year-old female (case no. 8 in the table) with methylmalonic acidemia. Diagnosed as a neonate, previous complications included severe renal failure and extrapyramidal movement disorders following earlier basal ganglia infarction. She presented with subacute bilateral decrease of visual acuity recorded at $6 / 60$ for right and left eyes and bilateral dyschromatopsia, noted concomitant to a severe episode of metabolic decompensation with initial normal fundoscopy and mildly subnormal acuities. Four months later, fundal pictures show bilateral disc pallor with asymmetric retinal nerve fibre layer thinning of $76 \mu \mathrm{m}$ in the right eye and $64 \mu \mathrm{m}$ in the left on OCT. At the time of the OCT, visual acuity had improved and was 6/9.5 and 6/30 for right and left eyes, respectively. 
Figure 3 Electrodiagnostics, from case 12 , showing absent flash and pattern flash visual evoked potentials (VEPs) (right column).

Electroretinogram (ERGs) were recorded in cases 6, 7 and 12 using corneal fibre electrodes and complied with international standards. Case 10 had ERGs recorded using skin electrodes, for reasons of compliance. Only case 12 is shown because the findings from the three other patients are remarkably similar. The light-adapted (cone) responses are attenuated to some extent but this is much greater in the dark-adapted state, suggesting a rod-mediated retinal dysfunction. The shaded areas in the ERG depict $95 \%$ Cls from our normative data set. The VEP data show 2 responses per condition.
ERG
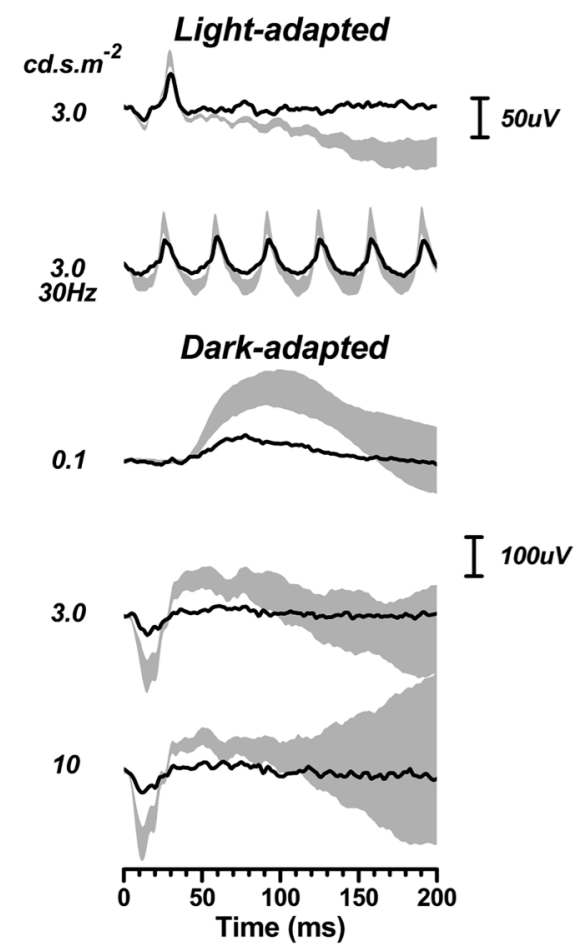

VEP

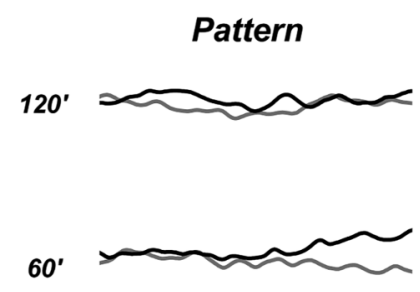

$30^{\prime}$

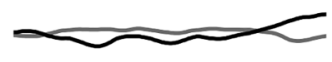

$15^{\prime}$
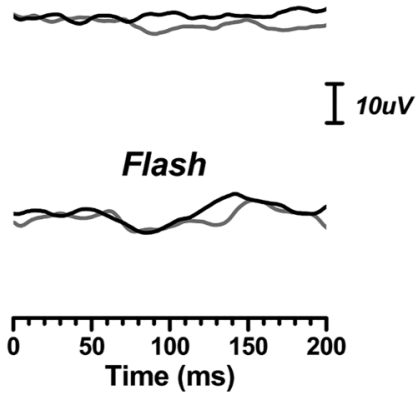

In our patients, and in the global group, presentation of the ON was variable, though all were bilateral and relatively symmetric. Older patients in the literature have mostly presented acutely with centro-cecal defects, temporal pallor and ultimately profound bilateral visual loss that has been compared with Leber's hereditary optic neuropathy (LHON). ${ }^{5} 7^{8}$ Younger patients in the literature, and the five males in our paediatric series, presented with progressive or undetermined visual deterioration, which may in part reflect the younger age and increased difficulty in reporting visual changes.

These similarities with mitochondrial $\mathrm{ON}$ are supported by the suspected pathophysiology of some of the complications. Mitochondrial dysfunction (primary or secondary to mitochondrial metabolite accumulation) is believed to play an important role, particularly underlying acute neurological symptoms (stroke-like episodes). ${ }^{2}{ }^{3}$ The observation of clinical features shared with mitochondrial disease (MD) and the biochemistry abnormalities during metabolic crisis further support this association. Currently, a number of in vitro, postmortem and murine model studies show strong evidence of mitochondrial malfunction in these patients. ${ }^{11-16}$ Murine models have suggested that both mitochondrial dysfunction and direct metabolite toxicity are synergistic in causing neural tissue damage in MMA. ${ }^{17}$

Other ON such as toxic-nutritional and toxic (eg, ethambutol-induced) can also result in selective initial damage to the papillomacular bundle with some scope for reversibility, especially if the optic atrophy is not established at diagnosis. This can also be true in LHON, which can show a degree of spontaneous recovery in some mutations. ${ }^{18}$ While the cases of acute presentation would be reminiscent of LHON, those that are insidious would be clinically more similar to other MD such as dominant optic atrophy (DOA), toxic or nutritional ON. Patient 10 in the literature series developed sensorineural hearing loss 3 months after presentation, and patient 3 had bilateral hearing loss. De Baulny et $a l^{2}$ mentioned two further patients with optic atrophy and sensorineural hearing loss, with no other details provided. In patients with other forms of MD or toxic neuropathy, both sensorineural hearing loss and $\mathrm{ON}$ are sometimes associated (eg, 20\% of families with DOA develop hearing loss, usually occurring later in life). ${ }^{19}$

Nutritional factors may also contribute to the $\mathrm{ON}$ in patients with MMA and PA. Poor weight gain due to protein restriction and anorexia are very common, often requiring gastrostomy tubes to supply part or all of the daily calories. This could contribute to the $\mathrm{ON}$ in a similar way as in toxic-nutritional $\mathrm{ON}$, with poor nutrition overlying a context of oxidative stress and toxic metabolites. Three of the patients reported in the literature had $\mathrm{B}$ group vitamins measured after vision loss, with only one showing slightly low levels of B1 and B6. ${ }^{78}$

Antibiotics are used in these patients to reduce the amount of propionate produced by gut bacteria, metronidazole being part of the treatment protocol for MMA and PA; ${ }^{1}$ all of our patients received lifelong treatment with this drug. While reversible ON has been reported in one patient after treatment for 8 months on metronidazole, ${ }^{20}$ peripheral autonomic, motor and sensory neuropathies are recognised side effects, particularly in high doses and long-term treatments.

Acute neurological and other complications in MMA and PA happen often during or shortly after recovery from a metabolic crisis. ${ }^{2}$ In our group, two of the children presented while suffering AMD, with three patients reported in the literature mentioning a recent AMD prior to vision loss..$^{79}$ In patient 8 of our series with MMA and AMD, VA improved spontaneously (without specific antioxidant treatment) after metabolic recovery and patient 12 received coenzyme Q10 (CoQ10) while in hospital, with no recovery in vision.

Three of the literature cases also had treatment trials with antioxidants: CoQ10 in one case and a combination of CoQ10 and vitamin $\mathrm{E}$ in the other two. One case treated with CoQ10 and vitamin $\mathrm{E}$, started 2 months after the vision loss, had visual 
Table 3 Clinical features of reported cases of optic atrophy in methylmalonic and propionic acidemia

\begin{tabular}{|c|c|c|c|c|c|c|c|c|}
\hline Case no. & $\mathrm{OA}$ & Gender & Age & Visual acuity RE & Visual acuity LE & Ophthalmic findings & Clinical presentation (acute/insidious) & Systemic involvement (available details) \\
\hline \multicolumn{9}{|c|}{ Williams et al } \\
\hline 1 & MMA & M & 16 & $20 / 300$ & $20 / 150$ & $\begin{array}{l}\text { Bilateral temporal ONP } \\
\text { Dyschromatopsia } \\
\text { OCT temporal thinning of papillomacular } \\
\text { bundle } \\
\text { Ceco-central scotomas }\end{array}$ & $\begin{array}{l}\text { Sequential bilateral acute loss of vision } \\
\text { with recent metabolic decompensation. } \\
\text { No response to CoQ10 }\end{array}$ & $\begin{array}{l}\text { Neonatal presentation } \\
\text { Well controlled } \\
\text { Renal failure 2nd decade life }\end{array}$ \\
\hline 2 & MMA & M & 21 & $20 / 200$ & $20 / 200$ & $\begin{array}{l}\text { Bilateral temporal ONP } \\
\text { Dyschromatopsia } \\
\text { Central scotomas }\end{array}$ & $\begin{array}{l}\text { Acute-bilateral loss of vision over } \\
1 \text { month }\end{array}$ & $\begin{array}{l}\text { Developmental delay+ } \\
\text { Wheelchair bound, basal ganglia anomalies in } \\
\text { imaging }\end{array}$ \\
\hline 3 & PA & $\mathrm{F}$ & 20 & $20 / 400$ & CF & $\begin{array}{l}\text { Bilateral optic atrophy } \\
\text { Dyschromatopsia }\end{array}$ & $\begin{array}{l}\text { Subacute with progressive decline over a } \\
\text { 4-month period }\end{array}$ & $\begin{array}{l}\text { Bilateral hearing loss } \\
\text { Developmental delay+ } \\
\text { Low B1 B6 levels }\end{array}$ \\
\hline \multicolumn{9}{|c|}{ Pinar-Sueiro et al } \\
\hline 4 & MMA & $\mathrm{F}$ & 15 & $6 / 38$ & $6 / 9.5$ & $\begin{array}{l}\text { Mild dyschromatopsia } \\
\text { Centro-cecal and diffuse scotoma } \\
\text { Delayed VEP } \\
\text { Initially normal ophthalmoscopy and OCT }\end{array}$ & $\begin{array}{l}\text { Fluctuating vision previous months, then } \\
\text { rapidly progressive bilateral asymmetric } \\
\text { ON, partially reversed with CoQ10 and } \\
\text { E vitamin }\end{array}$ & Neonatal presentation \\
\hline \multicolumn{9}{|l|}{ Arias et al } \\
\hline 5 & PA & M & 13 & $1 / 120$ & $1 / 120$ & $\begin{array}{l}\text { Bilateral optic atrophy } \\
\text { Severe concentric scotomas (kinetic perimetry) }\end{array}$ & Undetermined bilateral visual loss & $\begin{array}{l}\text { Diagnosis infancy ( } 4 \text { months) } \\
\text { Developmental delay }++ \\
\text { Seizures } \\
\text { Poor control }\end{array}$ \\
\hline 6 & PA & $\mathrm{F}$ & 18 & $20 / 800$ & $20 / 800$ & Bilateral optic atrophy & Progressive bilateral visual loss & $\begin{array}{l}\text { Diagnosis infancy (11 months) } \\
\text { Poor control } \\
\text { Developmental delay }+\end{array}$ \\
\hline \multicolumn{9}{|c|}{ lanchulev et al } \\
\hline 7 & PA & M & 2 & Fix and follow light & Fix and follow light & Bilateral asymmetric ONP & Undetermined (detected on screening) & $\begin{array}{l}\text { Developmental delay } \\
\text { Hypotonia }\end{array}$ \\
\hline 8 & PA & M & 9 & LP & Fix and follow toy & Morning glory RE and left ONP & Undetermined (detected on screening) & Hypotonia \\
\hline 9 & PA & M & 10 & $20 / 200$ & $20 / 200$ & Severe bilateral ONP & Undetermined (detected on screening) & None \\
\hline \multicolumn{9}{|c|}{ Traber et al } \\
\hline 10 & MMA & $\mathrm{F}$ & 23 & $\mathrm{CF}$ & $\mathrm{CF}$ & $\begin{array}{l}\text { Centro-cecal scotomas } \\
\text { Normal fundoscopy } \\
\text { VEP prolonged latency in BE }\end{array}$ & $\begin{array}{l}\text { Acute rapid onset of profound bilateral } \\
\text { visual loss, with further deterioration at } \\
6 \text { months } \\
\text { Optic enhancement MRI } \\
\text { No response to CoQ10 and vitamin E }\end{array}$ & $\begin{array}{l}\text { Neonatal presentation } \\
\text { Mild developmental delay } \\
\text { Renal impairment } \\
\text { Impaired growth } \\
\text { Hyperintense in T2 and enhancing MRI lesions } \\
\text { Sensorineural hearing loss }\end{array}$ \\
\hline \multicolumn{9}{|c|}{ Noval et al } \\
\hline 11 & PA & M & 24 & $20 / 160$ & $\mathrm{CF}$ & $\begin{array}{l}\text { Bilateral temporal ONP } \\
\text { Selective atrophy of the temporal quadrant } \\
\text { on OCT }\end{array}$ & $\begin{array}{l}\text { Bilateral visual loss after metabolic } \\
\text { decompensation triggered by elective } \\
\text { surgery }\end{array}$ & $\begin{array}{l}\text { Neonatal presentation } \\
\text { Cardiomyopathy } \\
\text { Mild developmental delay }\end{array}$ \\
\hline
\end{tabular}

BE, both eyes; CF, counting fingers; CoQ10, coenzyme Q10; F, female; LE, left eye; LP, light perception; M, male; MMA, methylmalonic acidemia; OCT, optical coherence tomography; ON, optic neuropathy; ONP, optic nerve pallor; PA, propionic acidemia; $\mathrm{RE}$, right eye; RNFL, retinal nerve fibre layer; VEP, visual evoked potentials. 
improvement. ${ }^{6}$ In another patient, only CoQ10 was administered, and in other the combination was given 7 months after onset, both with no benefit. $^{78}$

Isolated administration of CoQ10 is being investigated as a treatment option for LHON; class I evidence has shown that it can improve outcomes in certain subtypes. ${ }^{19}$ Recent investigation on a murine MMA model showed that an oral combination of CoQ10 and vitamin $\mathrm{E}$ improved the rate of decline of glomerular filtration rate in two comparable groups of MMA mutant mice fed with high protein concentration. ${ }^{21}$ This experimental evidence, alongside the anecdotal evidence, would support the opening of research into future treatment options for $\mathrm{ON}$ in $\mathrm{PA}$ and MMA.

Ianchulev et $a l^{4}$ suggested that optic atrophy in PA may have a preponderance for males. Out of all the reported cases for both conditions (our series included), there was a male preponderance of 2:1 with 12 males and 6 females; 5 males/3 females for MMA and 7 males/ 3 females for patients with PA. Given the small amount of published cases, it is difficult to know if this has any significance. Of the only two patients in this series with visual improvement, both were females and had MMA; one had early treatment with CoQ10 and E vitamin, ${ }^{6}$ while the other (patient 8) improved with only metabolic stabilisation.

All four patients with clinical ON who had electrodiagnostics had very reduced or absent VEP as would be expected in advanced optic atrophy, but interestingly also had grossly reduced dark-adapted ERGs, with relative preservation of the light-adapted response. They all had established visual loss and poor acuities-worse than would be expected from the ERG alone-pale nerves and unremarkable retinas on fundoscopy. Photoreceptor dysfunction has not been previously reported in MMA (excluding CblC subtype) or PA, with only delayed VEP reported $^{6}{ }^{8}$ and should be investigated further. A similar ERG could be found in coexistent vitamin A deficiency, which was not tested for, though a toxic cause or a mitochondrial dysfunction-mediated occult retinopathy, such as are presumed to cause $\mathrm{ON}$ and other complications, would be potential factors. Visual fields were not performed in our patients.

In conclusion, our series suggests that the incidence of $\mathrm{ON}$ with severe visual impairment is significant in MMA and PA. Clinical presentation is variable, with progressive and sudden onset being possible. Periodic ophthalmological screening is therefore important to determine the presence of visual impairment, particularly in children and in patients with developmental delay. As the treatment modalities and survival of these patients improve, the recognition of this complication is likely to increase.

More dedicated studies are needed to identify the prevalence of $\mathrm{ON}$ in these conditions to determine the extent and prevalence of photoreceptor involvement and determine the possible influence of nutritional deficiencies. Based on clinical observation, experimental and postmortem evidence, the aetiology of ON in these patients seems likely to stem from mitochondrial malfunction; however, a multifactorial aetiology remains possible.
Acknowledgements This study was facilitated by the Manchester Biomedical Research Centre and the Greater Manchester Comprehensive Local Research Network. We are grateful to Claire Delaney, Lis Nichol and Lindsi Williams for the electrodiagnostic workups. Wai Chan contributed to the original concept for this manuscript.

Contributors All co-authors listed in this article have been directly involved with either data collection, review of literature or preparation of the manuscript.

Competing interests None declared.

Provenance and peer review Not commissioned; externally peer reviewed.

\section{REFERENCES}

1 Grünert SC, Müllerleile S, De Silva L, et al. Propionic acidemia: clinical course and outcome in 55 pediatric and adolescent patients. J Rare Dis 2013;8:6.

2 De Baulny HO, Benoist JF, Rigal O, et al. Methylmalonic and propionic acidemias: management and outcome. J Inherit Metab Dis 2005;28:415-23.

3 Nizon M, Ottolenghi C, Valayannopoulos V, et al. Long-term neurological outcome of a cohort of 80 patients with classical organic acidurias. J Rare Dis 2013;8:148.

4 Ianchulev T, Kolin T, Moseley K. Optic nerve atrophy in propionic acidemia. Ophthalmology 2003;110:1850-4.

5 Arias $C$, Raimann $E$, Peredo $P$, et al. Propionic acidemia and optic neuropathy: a report of two cases. JIMD 2014;12:1-4.

6 Pinar-Sueiro S, Martínez-Fernández R, Lage Medina S, et al. Optic neuropathy in methylmalonic acidemia: the role of neuroprotection. J Inherit Metab Dis 2010;33 (Suppl 3):S199-203.

7 Williams ZR, Hurley PE, Altiparmak UE, et al. Late onset optic neuropathy in methylmalonic and propionic acidemia. Am J Ophthalmol 2009;147:929-33.

8 Traber G, Baumgartner MR, Schwarz U, et al. Subacute bilateral visual loss in methylmalonic acidemia. J Neuro-Ophthalm 2011;31:344-6.

9 Noval S, Lopez-Rodriguez M, Gonzalez-Sanchez E, et al. Late optic neuropathy in propionic academia following surgical intervention. J Neuroophthalmol 2013;33:90-1.

10 Tsina EK, Marsden DL, Hansen RM, et al. Maculopathy and retinal degeneration in cobalamin C methylmalonic aciduria and homocystinuria. Arch Ophthalmol 2005:123:1143-6.

11 Keyzer YD, Valayannopoulos V, Benoist JF, et al. Multiple OXPHOS deficiency in the liver, kidney, heart, and skeletal muscle of patients with methylmalonic aciduria and propionic aciduria. Pediatr Res 2009;66:91-5.

12 Fragaki K, Cano A, Benoist JF, et al. Fatal heart failure associated with CoQ10 and multiple OXPHOS deficiency in a child with propionic acidemia. Mitochondrion 2011;11:533-6.

13 Chandler RJ, Zerfas PM, Shanske S, et al. Mitochondrial dysfunction in mut methylmalonic acidemia. FASEB J 2009;23:1252-61.

14 Schwab MA, Sauer SW, Okun JG, et al. Secondary mitochondrial dysfunction in propionic aciduria: a pathogenic role for endogenous mitochondrial toxins. Biochem J 2006;398:107-12.

15 Mardach R, Verity MA, Cederbaum SD. Clinical, pathological, and biochemical studies in a patient with propionic acidemia and fatal cardiomyopathy. MolGenet Metab 2005;85:286-90.

16 Wajner M, Goodman SI. Disruption of mitochondrial homeostasis inorganic acidurias: insights from human and animal studies. J Bioenerg Biomembr 2011;43:31-8.

17 Okun JG, Hörster F, Farkas LM, et al. Neurodegeneration in methylmalonic aciduria involves inhibition of complex II and the tricarboxylic acid cycle and synergistically acting excitotoxicity. J Biol Chem 2002;277:14674-80.

18 Klopstock T, Yu-Wai-Man P, Dimitriadis K, et al. A randomized placebo-controlled trial of idebenone in Leber's hereditary optic neuropathy. Brain 2011;134(Pt 9):2677-86.

19 Amati-Bonneau P, Valentino ML, Reynier $\mathrm{P}$, et al. OPA1 mutations induce mitochondrial DNA instability and optic atrophy 'plus' phenotypes. Brain 2008;131:338-51.

20 McGrath NM, Kent-Smith B, Sharp DM. Reversible optic neuropathy due to metronidazole. Clin Experiment Ophthalmol 2007;35:585-6.

21 Manoli I, Sysol JR, Li L, et al. Targeting proximal tubule mitochondrial dysfunction attenuates the renal disease of methylmalonic academia. Proc Natl Acad Sci USA 2013; 110:13552-7 